P165 (continued)

and know the serving sizes of FV $(\mathrm{p}=.011)$ at baseline compared to follow-up. The focus group responses revealed that environmental and monetary barriers hindered their purchase of healthy foods, but that social enablers such as cooking together helped them eat healthier.

Conclusions and Implications: Results demonstrated that a nutrition intervention can promote a positive change in dietary/purchasing habits and revealed important information about the homeless individuals' nutritional lifestyle. Further research will be necessary to discover the degree to which positive nutrition knowledge and behavioral changes are retained by transitional populations.

Funding: None

\section{P166 Road to a Healthy Alabama: Policy, System and Environmental Strategies to Increase Access and Appeal of Healthy Foods}

Alicia R. Powers, PhD, arp0042@auburn.edu, Alabama Cooperative Extension System/Auburn University, ACES 206 Duncan Hall, Auburn University, AL 36849; Barb Struempler, PhD, Alabama Cooperative Extension System/Auburn University; Sondra Parmer, PhD; Katie Funderburk, MS, RD, MS; Ruth W. Brock, MEd; Jamie Griffin, MS, RD; Cecilia Tran, BS;

Krysta P. Kellegrew, BS, RD

Objective: According to Social Ecological Model tenets, policy, system and environmental (PSE) strategies have the potential to further the impact of direct education traditionally implemented in nutrition education. The Supplemental Nutrition Assistance Program - Education (SNAP-Ed) in Alabama is implementing broad scale, yet coordinated, PSE strategies to facilitate positive changes to state and local food and physical activity environments serving low-income individuals.

Description and Evaluation: To increase access and appeal of healthy foods, more than $90 \%$ of the 32 Alabama SNAP-Ed educators fostered at least one PSE change in 2016 with more than 170 efforts being initiated. Alabama SNAP-Ed launched 39 healthier retail efforts focused on improvements in product placement and inclusion of pointof-purchase prompts, reaching more than 20,000 residents each day. Another strategy established new gardens, reinvigorated current gardens and supported existing gardens. A total of 37 raised bed or row gardens now provide access to healthy foods for almost 5,000 residents in rural communities. A variety of policy, system and promotional changes were accomplished in 37 farmers markets, reaching more than 5,000 residents each week. Policies influencing location and hours of operation were key strategies as well as a system change to support vendor acceptance of SNAP benefits. Point-of-decision prompts were included in packages distributed by 58 emergency food assistance sites, reaching more than 12,000 Alabama residents.

Conclusions and Implications: A consistent approach to engage, assess, plan, implement, evaluate, celebrate and sustain was important. State level coordination of resources, assessment and evaluation are key to ensuring collective impact to benefit the health of Alabamians.
Funding: Supplemental Nutrition Assistance Program Education

\section{P167 Using GIS Mapping to Pinpoint and Plan Nutrition Education Sites}

Sharon Austin, MD, sharonaustin@ufl.edu, University of Florida IFAS Extension, 1408 Sabal Palm Drive, 2nd Floor, PO Box 110320, Gainesville, FL 32611; Nicole Owens, PhD, University of Florida IFAS Extension; Elder Garcia, MA, MPA; Lauren Headrick, MS, RD; Karla Shelnutt, PhD, RD

Objective: To use Geographic Information Systems (GIS) to map SNAP recipient addresses to determine SNAP-Ed programming locations.

Rationale: GIS mapping can be a useful tool to identify target areas for SNAP-Ed programming based on SNAP recipient population density.

Description: The University of Florida/IFAS Extension Family Nutrition Program (FNP) (Florida's SNAP-Ed program), conducted GIS spatial analysis and mapping to determine SNAP recipient population density in MiamiDade County, where 20\% of the SNAP recipients in Florida reside. SNAP recipient household addresses and FNP education sites were displayed on county maps.

Evaluation: Maps were analyzed to determine whether current FNP programming was offered where SNAP recipients live and to identify future FNP programming sites based on SNAP household density. The GIS mapping displayed various patterns of spatial distribution between FNP programming and SNAP household density. FNP programming was split between the southern and northern regions of Miami-Dade County while most of the SNAP households were in the northern region. The southern region's sites demarcated SNAP household density average of about 100 households in close proximity. The northern region's sites average 500 households in the same area.

Conclusion: GIS mapping visually displayed ranges of FNP programming locations in relationship to SNAP household density. Based on these data, FNP has targeted more education efforts in the northern region. FNP will utilize this valuable resource for strategic planning to reach more SNAP recipients throughout Florida.

Funding: Supplemental Nutrition Assistance Program Education

\section{P168 Worksite Wellness: Assessment of Need and Readiness for Policy, Systems, and Environmental Change}

Katlyn Bruecker, BS, kbruecker@michiganfitness.org, Michigan Fitness Foundation, 1213 Center Street, East Lansing, MI 48906; Kathleen Cullinen, PhD, RDN, Michigan Fitness Foundation

Objective: Identify priority areas for policy, systems, and/ or environmental change (PSE) at low-wage worksites participating in Michigan's SNAP-Ed Program to improve 